\title{
Characterization of phenolic compounds, total phenolic content and antioxidant activity of three Achillea species
}

\author{
Selman ŞABANOĞLU 1 (D), Alper GÖKBULUT 1 * (D) , M. Levent ALTUN 1 (D) \\ 1 Department of Pharmacognosy, Faculty of Pharmacy, Ankara University, 06100 Ankara, Turkey. \\ * Corresponding Author. E-mail: alpergkb78@hotmail.com (A.G.); Tel. +09-312-203 3087.
}

Received: 21 September 2018/ Revised: 23 January 2019 / Accepted: 26 January 2019

\begin{abstract}
Medicinal plants used in traditional medicine have been increasingly noticed within recent years in pharmaceutical, cosmetic and nutraceutical industry. Herein, methanolic extracts of Achillea biebersteinii Afan., A. setacea Waldst. Et Kit. and A. wilhelmsii C. Koch were investigated for their total phenolic content and antioxidant activity with the main focus on phenolics. The total phenolic content varied widely in different parts of the three tested Achillea species, ranging from $113.2 \pm 1.9$ to $178.4 \pm 9.5 \mathrm{mg}$ GAE/g extract using Folin Ciocalteu method. DPPH and ABTS antioxidant activity tests were used to evaluate and compare the antioxidant activity of the species. Both the DPPH and ABTS assay results revealed that the radical scavenging activity of A. biebersteinii leaf extract is remarkably high with $\mathrm{IC}_{50}$ values of $0.377 \pm 0.011$ and $0.016 \pm 0.002 \mathrm{mg} / \mathrm{mL}$, respectively. Furthermore, a newly validated RP-HPLC-DAD method was developed and used to determine the phenolic compound profile of the methanol extracts. Phenolic components, such as gallic acid, chlorogenic acid, caffeic acid, ferulic acid, $p$-coumaric acid, rutin, quercetin, luteolin, apigenin and kaempferol were analyzed by HPLC-DAD. The significant antioxidant properties of the extracts could be attributed to the phenolics of the Achillea species.
\end{abstract}

KEYWORDS: ABTS; Achillea; DPPH; HPLC-DAD; phenolic compounds.

\section{INTRODUCTION}

Latin name of Achillea comes from the name of Achilles, who healed the wounds by means of Achillea herb at the time of the Trojan War. The genus Achillea (Asteraceae) comprises more than 100 species widespread in Northern hemisphere. Achillea species have been characterized by a high content and diversity of terpenes, flavonoids, coumarins, phenolic acids, lignans and essential oil some of which are responsible for the antioxidant, estrogenic, antispermatogenic, antiulcerogenic, antimicrobial, antiviral, antispasmodic, immunosuppressive, antitumor and antidiabetic activities [1,2]. Various species of the genus are traditionally used in Turkey for wound healing, against diarrhea and flatulence, as a diuretic, as emmenagogue agents, and for abdominal pain $[3,4]$.

The chemical activity of phenolic compounds in terms of their reducing properties as hydrogen or electron-supplying agents displays their potential for action as free-radical scavengers. The commercial development of plants as sources of antioxidants which can be used to enhance the properties of foods, cosmetics and pharmaceuticals for both nutritional purposes and for prevention of diseases, is currently of high interest. Various epidemiological investigations have shown an inverse relationship between the intake of natural antioxidants and the frequency of chronic diseases such as coronary heart disease and certain cancers [5-7].

The need for such a study is especially for quantifying the antioxidant constituents of different parts of three Achillea taxa which should contribute positively to the above mentioned activities together with evaluating the antioxidant potential. Therefore, the aim of this study is to evaluate the total phenolic content and antioxidant activity of flowers, leaves and roots of three Achillea species, as well as to determine the phenolic components such as gallic acid, chlorogenic acid, caffeic acid, ferulic acid, $p$-coumaric acid, rutin, quercetin, luteolin, apigenin and kaempferol qualitatively and quantitatively using a new developed and validated HPLC-DAD method.

How to cite this article: Şabanoğlu S, Gökbulut A, Altun ML. Characterization of phenolic compounds, total phenolic content and antioxidant activity of three Achillea species. J Res Pharm. 2019; 23(3): 567-576. 


\section{RESULTS}

\subsection{Total phenolic content}

Total phenolic content of the Achillea species estimated using Folin Ciocalteu reagent was expressed as milligrams of gallic acid equivalents (GAE). Table 1 summarizes that total phenolic content of the different parts of the species varied widely, ranging from $113.2 \pm 1.9$ and $178.4 \pm 9.5 \mathrm{mg}$ GAE/g extract. A. biebersteinii leaf extract exhibited the highest total phenolic content together with A. setacea leaf and root extract and $A$. wilhelmsii leaf extract.

\subsection{DPPH radical scavenging activity}

The $\mathrm{IC}_{50}$ values of scavenging DPPH radicals for all the Achillea extracts were varying in the range of $377-1500 \mu \mathrm{g} / \mathrm{mL}$. Although the antioxidant potential of the extracts was found to be lower than Trolox (a water soluble vitamin E analogue), A. biebersteinii leaf extract showed apparent DPPH radical scavenging activity A. setacea leaf and root extracts exhibited prominent radical scavenging activity subsequent to $A$. biebersteinii leaf extract.

\subsection{ABTS radical scavenging activity}

All the Achillea ectracts scavenged ABTS radical in a concentration-dependent way (IC $\mathrm{C}_{50}: 16-432 \mu \mathrm{g} / \mathrm{mL}$ ) and the results were given in Table 1 . Leaf extract of A. biebersteinii exhibited prominent ABTS radical scavenging activity with an $\mathrm{IC}_{50}$ of $16 \mu \mathrm{g} / \mathrm{mL}$ which was found to be lower than Trolox $\left(\mathrm{IC}_{50}: 43 \mu \mathrm{g} / \mathrm{mL}\right)$. In parallel, the highest total phenolic content was determined for A. biebersteinii leaf extract, for which the lowest $\mathrm{IC}_{50}$ value was obtained. Though the total phenolic content of $A$. biebersteinii leaf extract was found so high among the investigated species, this significant radical scavenging activity should be attributed to phenolics. On the other hand, the least ABTS radical scavenging activity was obtained from the flower extract of A. setacea with an $\mathrm{IC}_{50}$ of $432 \mu \mathrm{g} / \mathrm{mL}$.

Table 1. Total phenol content and $\mathrm{IC}_{50}$ values of methanol extracts of three Achillea species according to DPPH and ABTS assays (Trolox $\mathrm{IC}_{50}(\mathrm{mg} / \mathrm{mL}): 0.042$ for DPPH and 0.043 for ABTS methods).

\begin{tabular}{|c|c|c|c|c|}
\hline & Species & $\begin{array}{l}\text { Folin Ciocalteu } \\
\text { (mgGAE/g extract) }\end{array}$ & $\begin{array}{l}\text { DPPHIC }_{50} \\
(\mathrm{mg} / \mathrm{mL})\end{array}$ & $\begin{array}{l}\text { ABTSIC }_{50} \\
(\mathrm{mg} / \mathrm{mL})\end{array}$ \\
\hline \multirow{3}{*}{ 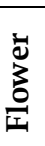 } & A.biebersteinii & $131.4 \pm 2.5$ & $0.670 \pm 0.044$ & $0.138 \pm 0.024$ \\
\hline & A. setacea & $121.2 \pm 4.4$ & $0.947 \pm 0.023$ & $0.432 \pm 0.003$ \\
\hline & A. wilhelmsii & $119.4 \pm 1.4$ & $1.500 \pm 0.024$ & $0.329 \pm 0.009$ \\
\hline \multirow{3}{*}{ Ш艹 } & A. biebersteinii & $178.4 \pm 9.5$ & $0.377 \pm 0.011$ & $0.016 \pm 0.002$ \\
\hline & A. setacea & $167.9 \pm 3.5$ & $0.470 \pm 0.002$ & $0.144 \pm 0.005$ \\
\hline & A. wilhelmsii & $155.5 \pm 8.7$ & $0.812 \pm 0.013$ & $0.214 \pm 0.001$ \\
\hline \multirow{3}{*}{$\stackrel{\overrightarrow{0}}{\check{\Xi}}$} & A. biebersteinii & $113.2 \pm 1.9$ & $0.773 \pm 0.053$ & $0.279 \pm 0.007$ \\
\hline & A. setacea & $154.1 \pm 5.6$ & $0.497 \pm 0.013$ & $0.143 \pm 0.004$ \\
\hline & A. wilhelmsii & $136.4 \pm 8.8$ & $0.991 \pm 0.017$ & $0.184 \pm 0.011$ \\
\hline
\end{tabular}

\subsection{RP-HPLC-DAD Analysis}

To precisely and exactly analyze six phenolic compounds in three Achillea species, a suitable HPLC method was established. In general, reverse phase columns were used to assay phenolic compounds in natural products. So that, we selected ACE $5 \mu \mathrm{C} 18(150 \times 4.60 \mathrm{~mm})$ column which is an efficient preference for separation of polar compounds. The mobile phase consisting of water (\% 0.2 trifloroacetic acid) pH: $2.4 \mathrm{~A}$, Acetonitrile : Methanol $(80: 20 \mathrm{v} / \mathrm{v}) \mathrm{B}$ was tested among various gradient systems and an adequate gradient ratio was selected. The composition of the gradient was (A:B), 95:5 at $0 \mathrm{~min}, 85: 15$ at $5 \mathrm{~min}, 85: 15$ at $15 \mathrm{~min}$, $80: 20$ at $20 \mathrm{~min}, 70: 30$ at $25 \mathrm{~min}, 65: 35$ at 30, 50:50 at $35 \mathrm{~min}$ and 95:5 at $39 \mathrm{~min}$. The UV wavelength of the DAD detector was set at 230, 330, 360, 340and $280 \mathrm{~nm}$. Most of the absorbed UV wavelength of each compound was selected in the UV spectrum. Chlorogenic and caffeic acids were analyzed at $330 \mathrm{~nm}$, luteolin was measured at $340 \mathrm{~nm}$, rutin, quercetin and apigenin were analyzed at $360 \mathrm{~nm}$. The peak of each compound was confirmed by comparing the retention time and UV spectrum of each analyzed compound with authentic ones. Moreover, authentic compounds were added to the extracts and the increase in the peaks were observed. 
Retention times for peaks of chlorogenic acid, caffeic acid, rutin, quercetin, luteolin and apigenin were 8.0, 8.9, 20.3, 29.2, 29.48, $32.66 \mathrm{~min}$, respectively (Figure 1). HPLC chromatograms of authentic compounds and extracts were given in Figure 2-4.

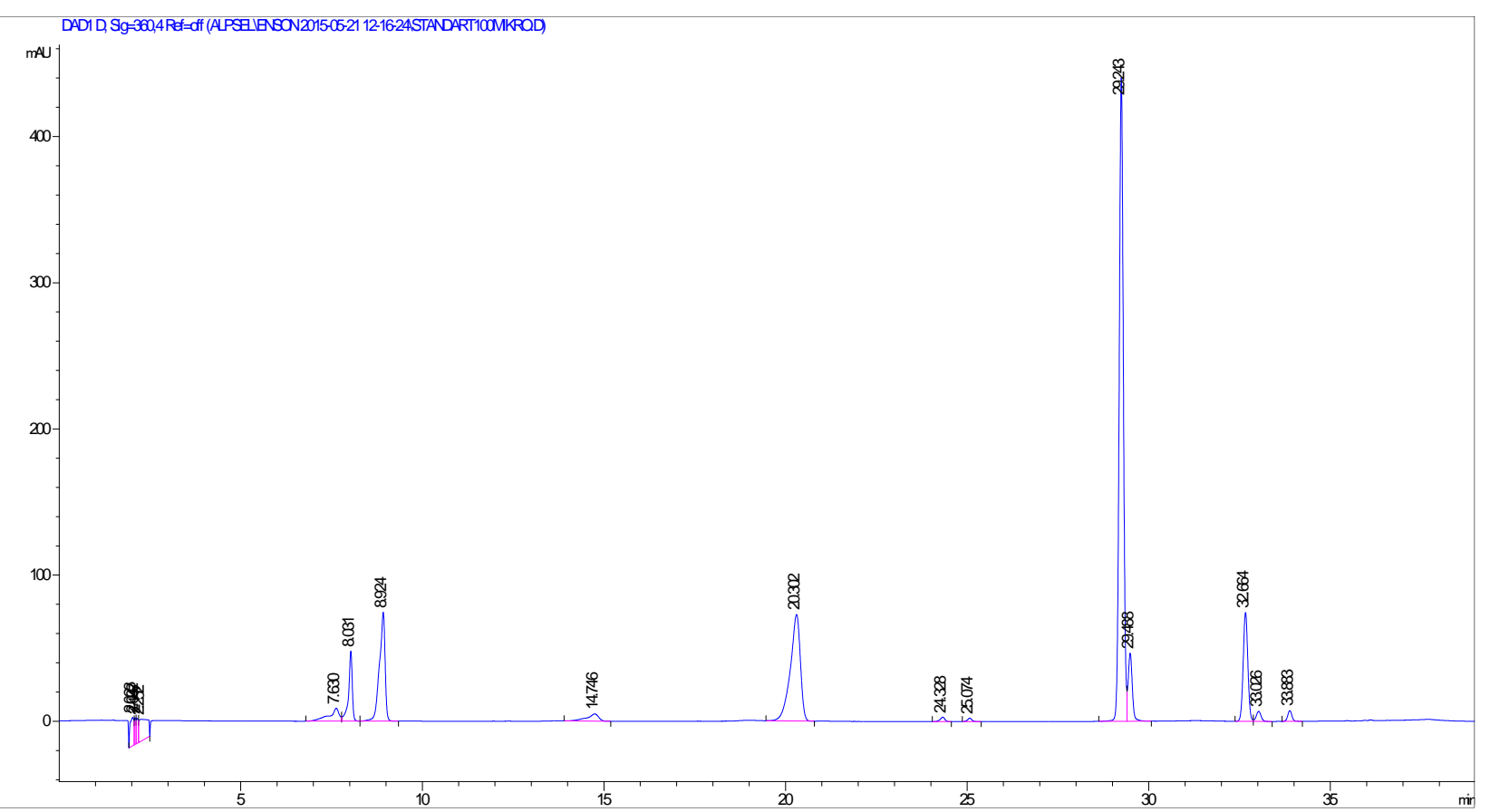

Figure 1. HPLC chromatogram of authentic phenolic compounds: Chlorogenic acid 8.0 min, caffeic acid 8.9 $\mathrm{min}$, rutin $20.3 \mathrm{~min}$, quercetin $29.24 \mathrm{~min}$, luteolin $29.48 \mathrm{~min}$, apigenin $32.66 \mathrm{~min}$.

This new method was validated and fine results were obtained. For the method validation, linearity was confirmed by the correlation coefficient $\left(R^{2}\right)$. To calculate the regression equation, five different concentrations of the standard solutions were used to establish calibration curves. The regression equation formed was $Y=a x+b$ ( $a$ - slope of the calibration curve, $b$ - intercept of the calibration curve); $Y$ axis was the value of peak area and $X$ axis was the concentration of phenolic compounds. The correlation coefficient of six phenolic compounds showed good linearity ( $\left.\mathrm{R}^{2}>0.9977\right)$. The RSD values for intra-day variations (repeatability) for chlorogenic acid, caffeic acid, rutin, quercetin, luteolin and apigenin were $2.54 \%, 1.40 \%$, $0.93 \%, 2.23 \%, 3.25 \%, 2.29 \%$, respectively. The RSD values for inter-day variations (intermediate precision) for chlorogenic acid, caffeic acid, rutin, quercetin, luteolin and apigenin were 5.98\%, 6.16\%, 2.53\%, 4.67\%, 6.13\%, $3.72 \%$, respectively. The recovery values were given in paranthesis for phenolic compounds: chlorogenic acid (88.9-98.8\%), caffeic acid (93.3-112\%), rutin (82.6-99.9\%), quercetin (93.4-111.8\%), luteolin (84.8-98.8\%) and apigenin (94.6-97\%). Retention times, linear relationships between peak areas and concentrations, test ranges, LOD and LOQ values were given in Table 2. The content of phenolic compounds in different parts of Achillea species were given in Table 3.

Table 2. Retention times, linear relationships between peak areas and concentrations, test ranges, LOD and LOQ.

\begin{tabular}{|c|c|c|c|c|c|c|}
\hline Analyte & $\begin{array}{l}\text { Retention } \\
\text { time (min) }\end{array}$ & Standard curve & $\mathbf{R}^{2}$ & $\begin{array}{l}\text { Test range } \\
(\mu \mathrm{g} / \mathrm{mL})\end{array}$ & $\begin{array}{l}\text { LODa }^{a} \\
(\mu \mathrm{g} / \mathrm{mL})\end{array}$ & $\begin{array}{l}\mathrm{LOQ}^{\mathrm{b}} \\
(\mu \mathrm{g} / \mathrm{mL})\end{array}$ \\
\hline Chlorogenic acid & 8.0 & $y=19008 x+5.2795$ & 0.9997 & $0.06-333$ & 0.0198 & 0.066 \\
\hline Caffeic acid & 8.9 & $y=62629 x+0.565$ & 0.9977 & $0.03-166$ & 0.0111 & 0.037 \\
\hline Rutin & 20.3 & $y=15129 x-39.937$ & 0.9991 & $6.6-333$ & 0.0066 & 0.022 \\
\hline Quercetin & 29.24 & $y=41336 x-6.5413$ & 0.9993 & $0.052-333$ & 0.0156 & 0.052 \\
\hline Luteolin & 29.48 & $y=40892 x-16.331$ & 0.9998 & $0.8-40$ & 0.0195 & 0.065 \\
\hline Apigenin & 32.66 & $y=41303 x-25.856$ & 0.9995 & $0.04-66$ & 0.0132 & 0.044 \\
\hline
\end{tabular}


Table 3. The content of phenolic compounds in Achillea species.

\begin{tabular}{|c|c|c|c|c|c|c|c|}
\hline \multicolumn{8}{|c|}{ Content $(\mathrm{g} / 100 \mathrm{~g} \mathrm{dw})$} \\
\hline & Species & $\begin{array}{c}\text { Chlorogenic } \\
\text { acid }\end{array}$ & Caffeic acid & Rutin & Quercetin & Luteolin & Apigenin \\
\hline \multirow{3}{*}{ 离 } & A.biebersteinii & $0.0519 \pm 0.0012$ & $0.0008 \pm 0.0004$ & $0.0205 \pm 0.0024$ & $0.0035 \pm 0.0001$ & $0.0240 \pm 0.0002$ & $0.0044 \pm 0.0001$ \\
\hline & A.setacea & $0.0707 \pm 0.0039$ & $\mathrm{Nd}$ & $0.0169 \pm 0.0004$ & $\mathrm{Nd}$ & $0.0293 \pm 0.0004$ & $0.0044 \pm 0.0001$ \\
\hline & A.willhelmsii & $0.0696 \pm 0.0009$ & $0.0021 \pm 0.0001$ & $0.0307 \pm 0.0015$ & $0.0036 \pm 0.0001$ & $0.0076 \pm 0.0001$ & $0.0034 \pm 0.0001$ \\
\hline \multirow{3}{*}{ 㫕 } & A.biebersteinii & $0.1094 \pm 0.0048$ & $0.0006 \pm 0.0001$ & $0.0527 \pm 0.0058$ & $0.0017 \pm 0.0001$ & $0.0042 \pm 0.0001$ & $\mathrm{Nd}$ \\
\hline & A.setacea & $0.1937 \pm 0.0003$ & $0.0007 \pm 0.0001$ & $0.1358 \pm 0.0033$ & $0.0018 \pm 0.0001$ & $0.0053 \pm 0.0001$ & $0.0041 \pm 0.0001$ \\
\hline & A.willhelmsii & $0.2745 \pm 0.0116$ & $0.0013 \pm 0.0001$ & $0.0202 \pm 0.0011$ & $\mathrm{Nd}$ & $\mathrm{Nd}$ & $\mathrm{Nd}$ \\
\hline \multirow{3}{*}{$\begin{array}{l}\ddot{0} \\
\stackrel{0}{\approx}\end{array}$} & A.biebersteinii & $0.1139 \pm 0.0004$ & $0.0018 \pm 0.0004$ & $\mathrm{Nd}$ & $\mathrm{Nd}$ & $\mathrm{Nd}$ & $\mathrm{Nd}$ \\
\hline & A.setacea & $0.4778 \pm 0.0213$ & $0.0083 \pm 0.0010$ & $\mathrm{Nd}$ & $\mathrm{Nd}$ & $\mathrm{Nd}$ & $\mathrm{Nd}$ \\
\hline & A.willhelmsii & $0.1328 \pm 0.0125$ & $0.0007 \pm 0.0001$ & $\mathrm{Nd}$ & $\mathrm{Nd}$ & $\mathrm{Nd}$ & $\mathrm{Nd}$ \\
\hline
\end{tabular}

\section{DISCUSSION}

A rich complex of biologically active compounds is responsible for the wide spectrum of biological activities of Achillea species [8]. In the last decades, interest in the antioxidant properties of Achillea genus is increasing, so that the assessment of total phenolic content and radical scavenging activity of these plants are of high importance.

Several in-vitro methods have been used to present the antioxidant activity of plant extracts and pure compounds in order to set light and plan in-vivo experiments [6]. In our study, DPPH and ABTS radical scavenging assays were preferred to determine the antioxidant activity of Achillea species. The radical scavenging potential of the extracts can be measured by evaluating 2,2'-diphenyl-1- picrylhydrazyl radical (purple-coloured) bleaching. The degree of bleeching is directly proportional to the potency and concentration of the antioxidants. Herein, among all the investigated species, A. biebersteinii leaf extract showed apparent DPPH radical scavenging activity together with $A$. setacea leaf and root extracts. In ABTS radical scavenging assay, a blue/green $\mathrm{ABTS}^{+}$chromophore occurs via the reaction of ABTS and $\mathrm{K}_{2} \mathrm{~S}_{2} \mathrm{O}_{8}$. The reduction of the ABTS radical cation in the presence of hydrogen-donating antioxidants is measured spectrophotometrically at $734 \mathrm{~nm}$. In this study, leaf extract of A. biebersteinii exhibited prominent ABTS radical scavenging activity with an $\mathrm{IC}_{50}$ of $16 \mu \mathrm{g} / \mathrm{mL}$. A. biebersteinii leaf extract was found to possess notable radical scavenging activity with both methods, and total phenolic content of the A. biebersteinii leaf extract was found very high among all the investigated extracts supporting our results that this activity could be due to the phenolics.

Phenolic compounds can be classified in several categories such as phenolic acids, flavonoids etc. Phenolic acids and flavonoids are naturally occuring secondary metabolites of the plants and most of the studies have shown their positive effects on public health. Phenolic compounds are supposed to be highly effective scavengers of most oxidizing molecules [9, 10]. Our results suggested that phenolic acids and flavonoids may be the major contributors for the radical scavenging activity of the Achillea extracts.

To present the active principles responsible for the antioxidant activity, reverse phase HPLC-DAD method was developed and validated. For the best separation, different combinations of solvent systems consisting of water, methanol and acetonitrile were tried using various flow rates. For method validation, linearity, precision, test range, detection and quantification limits and recovery values were calculated. In approximetaly 35 minutes, two phenolic acids and 4 flavonoids were well separated and quantified by this newly developed method. Other compounds such as gallic acid, $p$-coumaric acid, ferulic acid and kaempferol were not detected in any of the investigated species. According to our HPLC results, rutin was determined in significant amount in A. setacea leaves while chlorogenic acid was one of the most abundant compound in the roots. Flavonoids were not detected in any of the investigated root samples. 


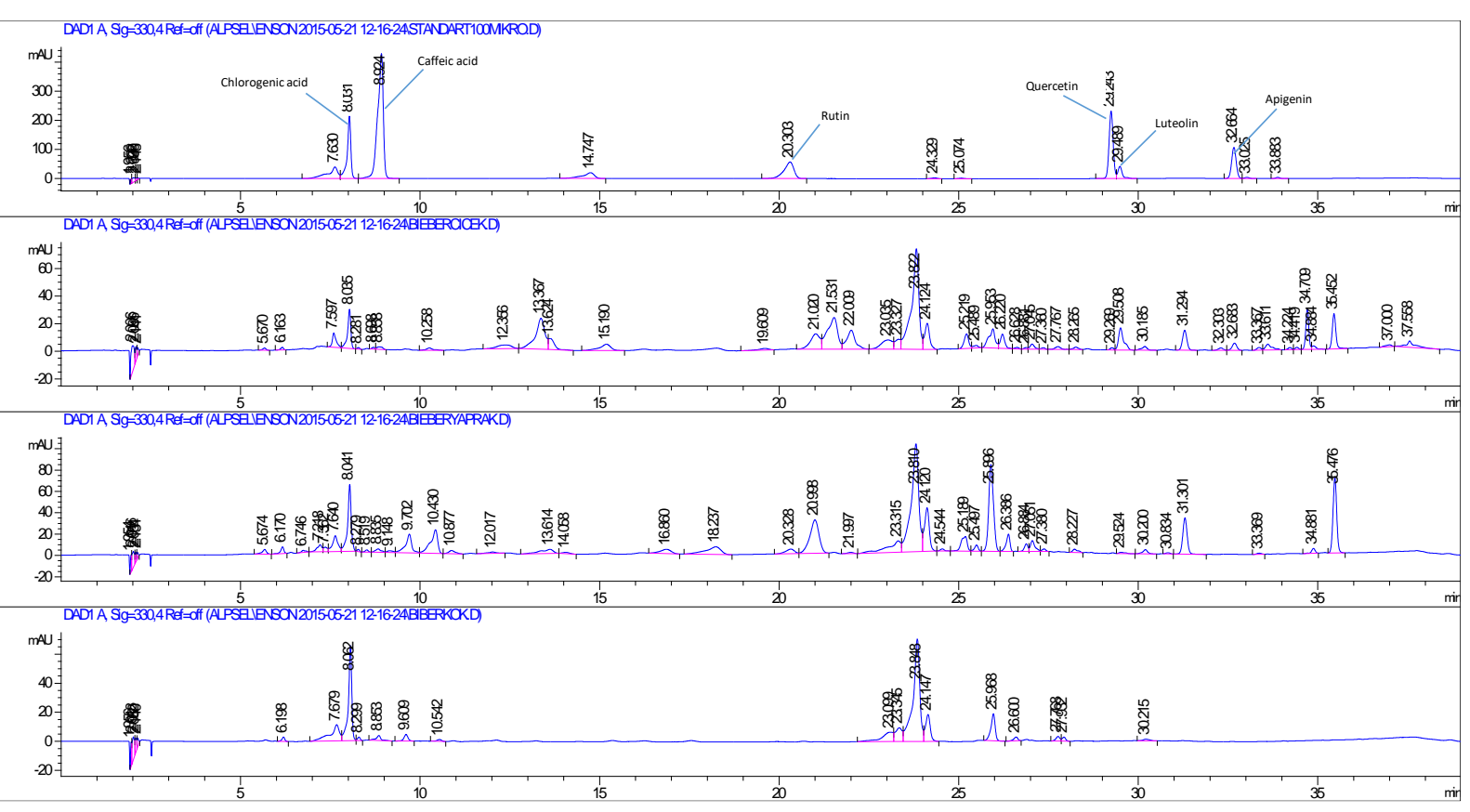

Figure 2. HPLC chromatograms of authentic phenolic compounds, and flower, leaf and root of A. Biebersteinii.

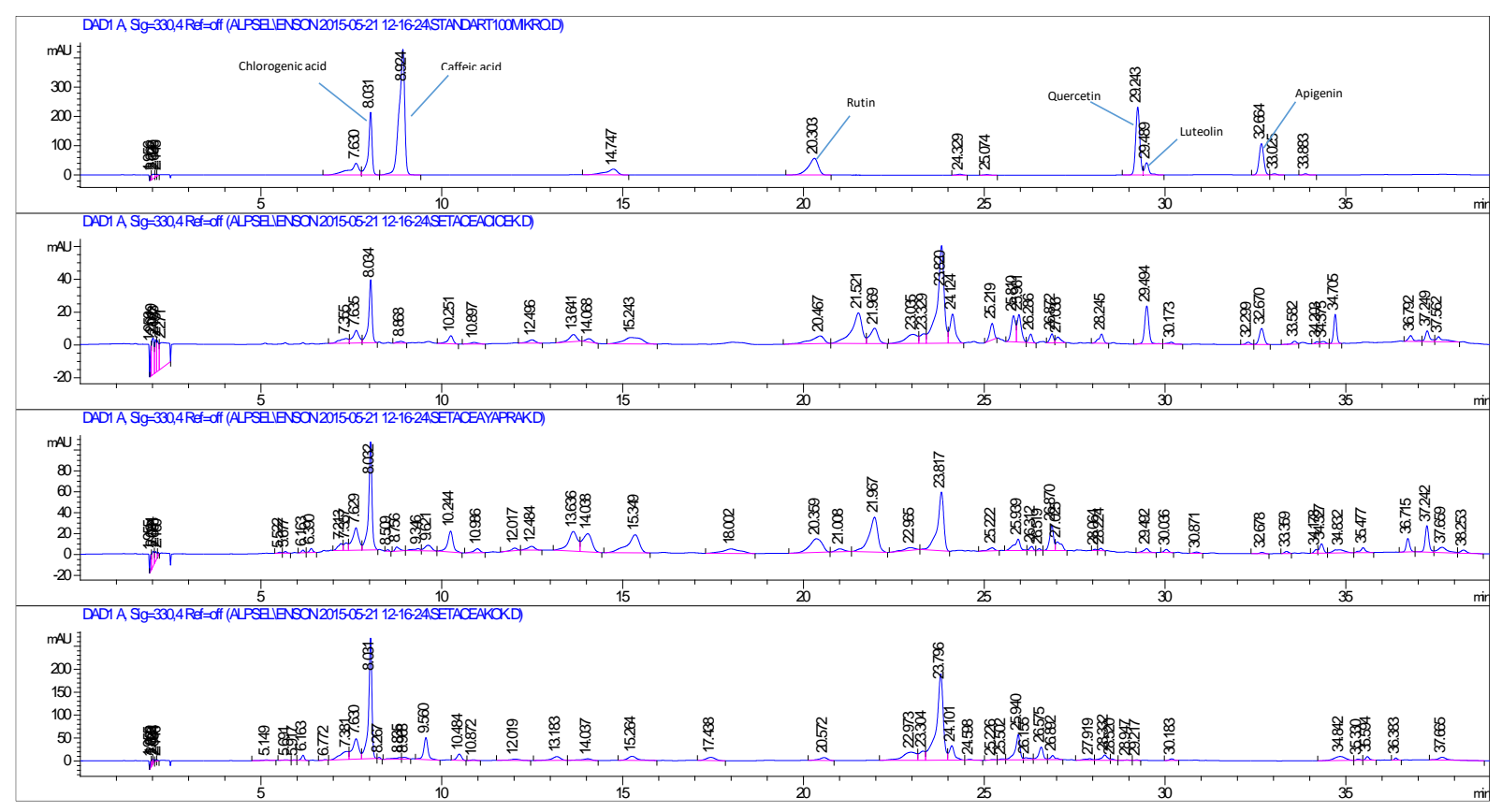

Figure 3. HPLC chromatograms of authentic phenolic compounds, and flower, leaf and root of A. setacea. 


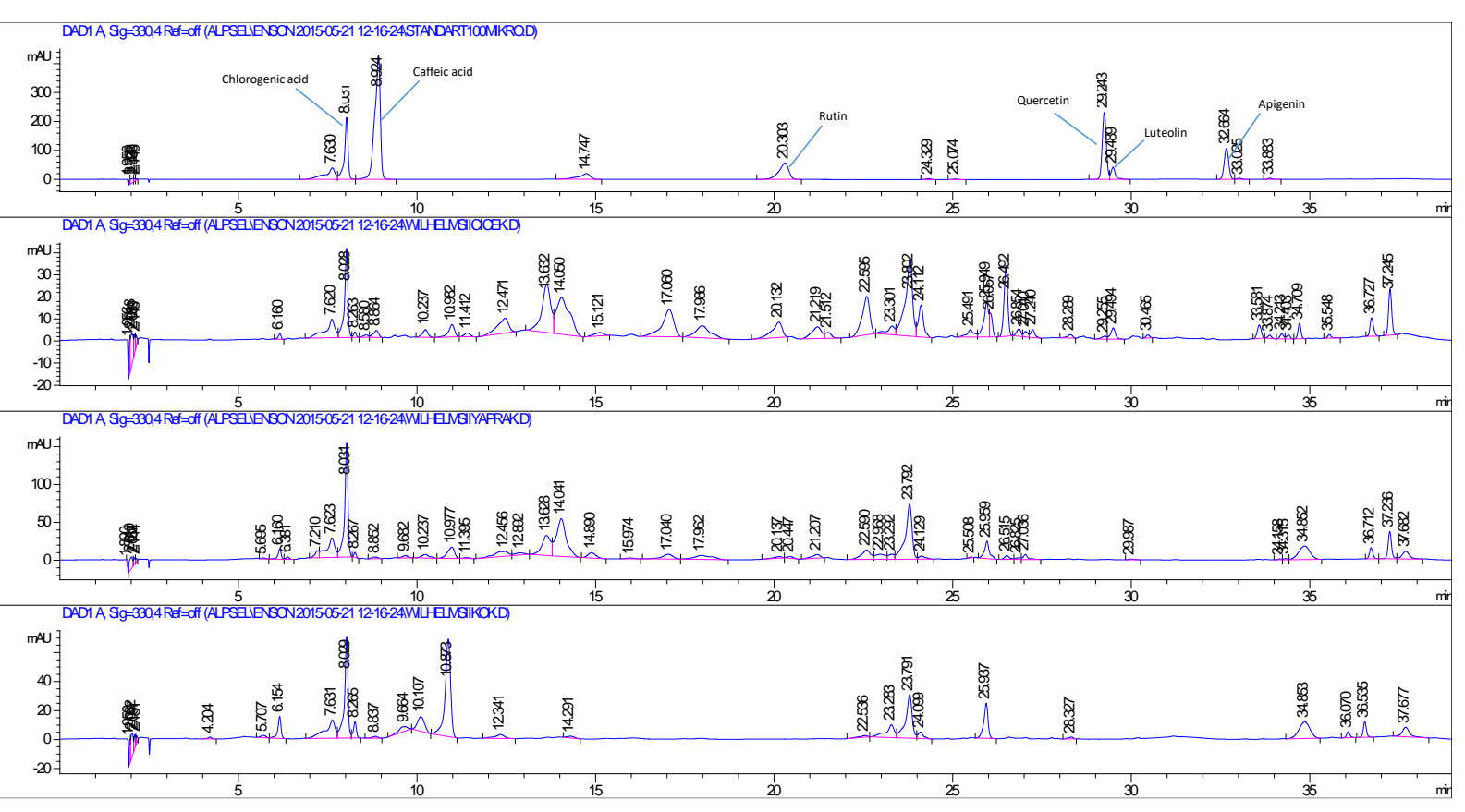

Figure 4. HPLC chromatograms of authentic phenolic compounds, and flower, leaf and root of A. wilhelmsii.

Researchers are mostly focused on A. millefolium and some other taxa of Achillea genus, so that some of the antioxidant activity assay results and phenolic composition of the species were summarized to see the distinction among the Achillea plants. Investigations on A. millefolium were summarized: Benetis et al. [8] quantified some phenolic compounds in A. millefolium and the results revealed that chlorogenic acid amount was $2.06 \mathrm{~g} / 100 \mathrm{~g}$, rutin was $0.27 \mathrm{~g} / 100 \mathrm{~g}$, luteolin was $0.015 \mathrm{~g} / 100 \mathrm{~g}$ and apigenin was $0.008 \mathrm{~g} / 100 \mathrm{~g}$ in the leaves of yarrow. Bobis et al. [11] determined total phenolic content and phenolic composition of A. millefolium and the results exhibited that chlorogenic acid amount was $0.001 \mathrm{~g} / 100 \mathrm{~g}$, rutin was $0.14 \mathrm{~g} / 100 \mathrm{~g}$ and luteolin was $0.09 \mathrm{~g} / 100 \mathrm{~g}$. The total phenolic content was determined as $134.65 \pm 9.52 \mathrm{mg}$ GAE/g dry weight of plant. Trumbeckaite et al. [12] analyzed the phenolic components of A. millefolium, and the results showed that chlorogenic acid $(1.93 \pm 0.13 \mathrm{~g} / 100 \mathrm{~g})$ predominated in the mixture of identified secondary metabolites. Regarding the composition of the flavonoid complex, the pattern of distribution in A. millefolium was characterised by the dominance of apigenin $(1.42 \pm 0.04 \mathrm{~g} / 100 \mathrm{~g})$ and luteolin $(1.02 \pm 0.03 \mathrm{~g} / 100 \mathrm{~g})$, whereas their glucosides were determined in considerably lower quantities. Furthermore, rutin $(0.32 \pm 0.01 \mathrm{~g} / 100 \mathrm{~g})$ was also found to be minor components amongst the identified flavonoids. Raudonis et al. [13] investigated some compounds in the extracts of A. millefolium that possessed radical-scavenging properties, and reported these compounds as chlorogenic acid, luteolin-7-O-glucoside, rutin, and luteolin. Vitalini et al. [14] investigated the phenolic composition and antioxidant activity of the methanol extract of A. millefolium, and determined the antioxidant compounds as chlorogenic acid, rutin, luteolin and apigenin glycosides. Investigations on A. biebersteinii and A. wilhelmsii were summarized and compared to our results: Fathi et al. [2] investigated antioxidant activity and phenolic content of the methanol extracts of $A$. wilhelmsii aerial parts and $\mathrm{IC}_{50}$ for DPPH radical-scavenging activity was revealed as $58.9 \pm 2.7 \mu \mathrm{g} / \mathrm{mL}$ and the total phenolic content was determined as $37.4 \pm 0.3 \mathrm{mg} \mathrm{GAE} / \mathrm{g}$ of extract. These findings are too low when compared to our results. Bashi et al. [15] investigated antioxidant activity and total phenolic contents of A. biebersteinii and A. wilhelmsii methanol extracts with different extraction methods and reported the total phenolic contents of the species in the ranges of 20.16-108.54 and 17.18-59.61 mg GAE/g extract, respectively. Ultrasonic extraction results are close to our findings. Baris et al. [16] investigated the antioxidant activity and total phenolic content of the ethanol extract of $A$. biebersteinii aerial parts and indicated that the $\mathrm{IC}_{50}$ for DPPH radical-scavenging activity was $33 \mu \mathrm{g} / \mathrm{mL}$, which was too low compared to our flower, leaf and root extract results. Total phenolic content was determined as $134 \mathrm{mg} \mathrm{GAE} / \mathrm{g}$ extract, which was close to our results. Ashgar et al. [17] examined the antioxidant activity of methanol extracts of various parts of $A$. wilhelmsii and their fractions. The methanol extract and different fractions of various parts of $A$. wilhelmsii were found to contain appreciable levels of total phenolic contents. The results of the study have shown significant variations in the antioxidant activities of various parts of $A$. wilhelmsii and their fractions which the results were in parallel to our findings. 
Investigations on some other Achillea species were displayed: Gharibi et al. [18] investigated total phenolic content and antioxidant activity of the methanolic extracts of the leaf samples of three Iranian endemic Achillea species. In DPPH assay, A. aucherii showed the highest IC $50(0.844 \mathrm{mg} / \mathrm{mL})$, while A. kellalensis and A. pachycephalla possessed $0.518 \mathrm{mg} / \mathrm{mL}$ and $0.248 \mathrm{mg} / \mathrm{mL}$, respectively. Benedec et al. [19] quantified some phenolic compounds and determined antioxidant activity of two A. distans subspecies. Chlorogenic acid content was found too low $(<0.0002 \mathrm{~g} / 100 \mathrm{~g})$ in both ssp. In the ethanolic extract of $A$. distans subsp. distans flowers, luteolin was the compound found in the largest amount $(0.763 \pm 0.001 \mathrm{~g} / 100 \mathrm{~g})$ followed by apigenin $(0.264 \pm 0.001 \mathrm{~g} / 100 \mathrm{~g})$. They detected quercetin at lower levels than major flavonoides $(0.0014 \pm 0.0001 \mathrm{~g} / 100$ $\mathrm{g})$. In the ethanolic extract of $A$. distans subsp. alpina luteolin amount was determined as $0.052 \pm 0.0001 \mathrm{~g} / 100 \mathrm{~g}$ while apigenin was found as $0.013 \pm 0.0001 \mathrm{~g} / 100 \mathrm{~g}$. The highest amount of the total polyphenols was determined in the extract of $A$. distans subsp. alpina flowers (174.75 $\pm 1.47 \mathrm{mg}$ GAE/g extract) followed by A.distans subsp. distans extract (101.61 $\pm 1.24 \mathrm{mg} \mathrm{GAE} / \mathrm{g}$ extract).

There are only a few studies on the phenolic composition of A. setacea. One of them, capillary electrophoretic seperation and quantification of flavone-O and C-glycosides in A. setacea were carried out, previously [20]. To the best of our knowledge, HPLC analysis of $A$. setacea on phenolic acids and flavonoids were performed first time in this study.

According to the literature given above, antioxidant activity and phenolic content of Achillea species are of great interest especially to the researchers who are trying to set light to the traditional usage of these plants against chronic diseases and to present the active principles responsible for the wide range of pharmacological activities.

\section{CONCLUSION}

The screening of antioxidant properties of three Achillea species by DPPH and ABTS assays revealed that they possessed significant antiradical activity, which was due to the presence of radical scavenging components that were quantified using a newly validated HPLC-DAD method. In other words, the phenolic compound profile of the $\mathrm{MeOH}$ extracts of Achillea species contributed to the definition of antioxidant activity of the plants. To the best of our knowledge, qualitative and quantitative analysis of phenolic compounds of $A$. setacea is reported here for the first time, as well as the results of radical scavenging activity tests and total phenolic content assay. The antioxidant activity values $\left(\mathrm{IC}_{50}\right)$ obtained from A. biebersteinii and A. wilhelmsii extracts were found notably high compared to the results obtained from the species of different countries. On the other hand, herein, different parts of the plants such as flowers, leaves and roots were studied separately in all experiment models to set light to the other researchers for efficient usage and evaluation of the plants. Consequently, due to the high content of phenolics, Achillea species could be evaluated as natural antioxidants in pharmaceutical, cosmetic and nutraceutical industry.

\section{MATERIALS AND METHODS}

\subsection{Chemicals}

Chromatographic grade double-distilled water, HPLC grade methanol, acetonitrile and analytical grade trifluoroacetic acid were used for HPLC analysis. Folin Ciocalteu reagent (F9252) and the following phenolic compounds were purchased from Sigma (Germany): gallic acid (G7384), chlorogenic acid (C3878), caffeic acid (C0625), ferulic acid (46278), p-coumaric acid (C9008), rutin (R5143), quercetin (Q4951), luteolin (L9283), apigenin (10798) and kaempferol (K0133). Also, DPPH (D9132) and ABTS (A1888) were purchased from Sigma (Germany). All other chemicals were analytical grade and obtained from either Sigma or Merck.

\subsection{Plant material}

Achillea biebersteinii Afan. (AEF 26686), A. setacea Waldst. Et Kit. (AEF 26688) and A. wilhelmsii C. Koch (AEF 26687) were collected near Yahyal1-Kayseri in their flowering stages (2014). Voucher specimens are deposited in the herbarium of Ankara University Faculty of Pharmacy (AEF).

\subsection{Extraction procedure}

For antioxidant activity tests, $5 \mathrm{~g}$ of dried and milled flowers, leaves and roots of the plants were extracted with methanol $(100 \mathrm{~mL}$ ) by magnetic stirrer for $6 \mathrm{~h}$ (room temperature, $250 \mathrm{rpm}$ ) [21]. After filtration, the organic phases were evaporated completely in a rotary evaporator (Buchi-R200). The crude extracts were used for antioxidant activity and total phenolic content assays. 
For HPLC analysis, $200 \mathrm{mg}$ of dried and milled flowers, leaves and roots were extracted with methanol, using a magnetic stirrer, for $6 \mathrm{~h}$ (room temperature, $250 \mathrm{rpm}$ ). The extracts were then filtered, made up to 10.0 $\mathrm{mL}$ in a volumetric flask with methanol, passed through a $0.45 \mu \mathrm{m}$ filter, and injected into the HPLC system.

\subsection{Determination of total phenolic content}

The total phenolic content of the extracts was determined spectrophotometrically using a modified Folin Ciocalteu method [22]. The reduction of the reagent, which resulted in the formation of a blue colour, was recorded at $765 \mathrm{~nm}$. One hundred $\mu \mathrm{L}$ of the methanol extract of each plant part $(2 \mathrm{mg} / \mathrm{mL})$ was mixed with $7.9 \mathrm{~mL}$ of distilled water. Folin Ciocalteu reagent $(500 \mu \mathrm{L})$ was added and the contents of the flask shaken vigorously. After $8 \mathrm{~min}, 1.5 \mathrm{~mL}$ of $20 \% \mathrm{Na}_{2} \mathrm{CO}_{3}$ was added. After $2 \mathrm{~h}$ incubation at room temperature, the absorbance was measured at $765 \mathrm{~nm}$ with a Shimadzu spectrometer. Gallic acid was used as standard. All measurements were performed in triplicate, and the average values were used to express the $\mathrm{mg}$ of gallic acid equivalents (GAE)/g dry extract.

\subsection{DPPH (1,1-diphenyl-2-picrylhydrazyl) radical scavenging activity}

The capacity to scavenge the stable free radical DPPH wasmonitored according to the modified method of Barros et al. [23]. Various concentrations of extracts $(0.25 \mathrm{~mL})$ were mixed with $2.75 \mathrm{~mL}$ of methanolic solution containing DPPH radical. The mixture was shaken vigorously and left to stand for $10 \mathrm{~min}$ in the dark (until stable absorption values were obtained). The reduction of the DPPH radical was determined by measuring the absorption at $517 \mathrm{~nm}$. The radical scavenging activity $(\mathrm{Inh} \%)$ was calculated as a percentage of DPPH discoloration using the equation: $\operatorname{Inh} \%=\left[\left(\mathrm{A}_{\mathrm{DPPH}}-\mathrm{A}_{\mathrm{s}}\right) / \mathrm{A}_{\mathrm{DPPH}}\right] \mathrm{X} 100$, where $\mathrm{A}_{\mathrm{s}}$ is the absorbance of the solution when the sample extract was added at a particular level, and $\mathrm{A}_{\mathrm{DPPH}}$ is the absorbance of the DPPH solution. The extract concentration providing $50 \%$ inhibition $\left(\mathrm{IC}_{50}\right)$ was calculated from the graph of inhibition percentage against extract concentration. Trolox (Sigma, Germany) was used as standard.

\subsection{ABTS [2,2'-azino-bis(3-ethylbenzthiazoline-6-sulphonic acid)] assay}

ABTS radical scavenging activity was measured using a modification of the method of Re et al. [24]. ABTS was dissolved in methanol to a concentration of $7 \mathrm{mM}$. ABTS radical cation was produced by reaction of ABTS stock solution with $2.45 \mathrm{mM} \mathrm{K}_{2} \mathrm{~S}_{2} \mathrm{O}_{8}$ (as an oxidant for conversion of ABTS into a radical cation). The color of the resulting solution was blue-green. This radical solution was kept in the dark at room temperature for 12-16 $\mathrm{h}$ before use in precise measurements. The ABTS radical cation solution was diluted with $96 \%$ ethanol to obtain an absorbance of $0.70 \pm 0.02$ at $734 \mathrm{~nm}$. An aliquot of each extract $(0.25 \mathrm{~mL})$ was mixed with $2.75 \mathrm{~mL}$ of diluted ABTS radical cation solution. After reaction at room temperature for $6 \mathrm{~min}$, the reduction in absorbance at $734 \mathrm{~nm}$ was measured. The radical scavenging activity (Inh\%) was calculated as a percentage of ABTS inhibition using the equation: Inh $\%=\left[\left(\mathrm{A}_{\mathrm{ABTS}}-\mathrm{A}_{\mathrm{s}}\right) / \mathrm{A}_{\mathrm{ABTS}}\right] \mathrm{X} 100$. The extract concentration providing $50 \%$ inhibition $\left(\mathrm{IC}_{50}\right)$ was calculated from the graph of inhibition percentage against extract concentration. Trolox (Sigma, Germany) was used as standard.

\subsection{RP-HPLC-DAD analysis}

\subsubsection{HPLC conditions}

RP-HPLC systems equipped with DAD are frequently used for qualitative and quantitative analysis of phenolic compounds, and one of our previous studies should be given as an instance for such studies [21]. In this study, analysis was performed on Agilent 1260 Series HPLC system which was equipped with a quaternary pump, an auto-sampler, a column oven, and a diode-array UV/VIS detector. Data analysis was performed using Agilent Chemstation software. The separation was executed on ACE $5 \mu$ C18 $(150 X 4.60 \mathrm{~mm}$ id) column. The mobile phase was composed of A: Water (\%0.2 trifloro acetic acid) pH: 2.4, B: Acetonitrile:Methanol $(80: 20 \mathrm{v} / \mathrm{v})$ with the gradient elution system at a flow rate of $0.9 \mathrm{~mL} / \mathrm{min}$. The composition of the gradient was (A:B), 95:5 at $0 \mathrm{~min}, 85: 15$ at $5 \mathrm{~min}, 85: 15$ at $15 \mathrm{~min}, 80: 20$ at $20 \mathrm{~min}, 70: 30$ at $25 \mathrm{~min}, 65: 35$ at 30, 50:50 at $35 \mathrm{~min}$ and $95: 5$ at $39 \mathrm{~min}$. The injection volume was $10 \mu \mathrm{l}$. The detection UV wavelength was set at 230, 330, 360, 340, and $280 \mathrm{~nm}$. The column temperature was set to $25^{\circ} \mathrm{C}$. Method validation was performed according to the ICH guideline [25].

\subsubsection{Calibration}

Five different concentrations of chlorogenic acid, caffeic acid, rutin, quercetin, luteolin and apigenin were prepared in methanol ranging between $0.066-333 \mu \mathrm{g} / \mathrm{mL}, 0.037-166 \mu \mathrm{g} / \mathrm{mL}, 6.6-333 \mu \mathrm{g} / \mathrm{mL}, 0.052-333$ 
$\mu \mathrm{g} / \mathrm{mL}, 0.8-40 \mu \mathrm{g} / \mathrm{mL}$ and $0.044-66 \mu \mathrm{g} / \mathrm{mL}$, respectively. Triplicate $10 \mu \mathrm{L}$ injections were made for each standard solution to see the reproducibility of the detector response at each concentration level. The peak areas obtained from injections were plotted against the concentrations to establish the calibration graph.

\subsubsection{Limits of detection and quantification}

Limits of detection (LOD) were established at a signal to noise ratio $(\mathrm{S} / \mathrm{N})$ of 3 . Limits of quantification (LOQ) were established at a signal to noise ratio $(\mathrm{S} / \mathrm{N})$ of 10 . LOD and LOQ were experimentally verified by the nine injections of reference compounds in LOQ concentrations.

\subsubsection{Precision}

The precision of the method (intra-day and inter-day variations of replicate determinations) was checked by injecting nine times of reference compounds at the LOQ levels in the same day and in two different days. The area values were recorded and RSD\% values were calculated.

\subsubsection{Recovery}

The spike recovery was carried out by the standard addition method. For the determination of the recovery from the methanol extract, three different concentrations of reference compounds were added prior to the extraction. In each additional level, six determinations were carried out and the mean value of recovery percentage was calculated.

Author contributions: Concept - S.Ş., A.G., M.L.A.; Design - S.Ş., A.G.; Supervision - A.G., M.L.A.; Materials - A.G., M.L.A.; Data Collection and/or Processing - S.Ş., A.G., M.L.A.; Analysis and/or Interpretation - S.Ş., A.G., M.L.A.; Literature Search - S.Ş., A.G., M.L.A.; Writing - S.Ş., A.G.; Critical Reviews - S.Ş., A.G., M.L.A.

Conflict of interest statement: No conflict of interest associated with this work.

\section{REFERENCES}

[1] Si XT, Zhang ML, Shi QW, Kiyota H. Chemical constituents of the plants in the genus Achillea. Chem Biodivers. 2006; 3: 1163-1180. [CrossRef]

[2] Fathi H, Lashtoo AB, Ebrahimzadeh MA. Antioxidant activity and phenolic contents of Achillea wilhemsii. Pharmacologyonline. 2011; 2: 942-949.

[3] Baytop T. Therapy with medicinal plants in Turkey. Sanal Press, Istanbul, 1984, pp.176-177.

[4] Karaalp C, Yurtman AN, Karabay YNU. Evaluation of antimicrobial properties of Achillea L. flower head extracts. Pharm Biol. 2009; 47: 86-91. [CrossRef]

[5] Shahidi F. Antioxidants in food and food antioxidants. Nahrung. 2000; 44: 158-163. [CrossRef]

[6] Antolovich M, Prenzler PD, Patsalides E, McDonald S, Robards K. Methods for testing antioxidant activity. Analyst. 2002; 127: 183-198. [CrossRef]

[7] Konyalığlu S, Karamenderes C. The protective effects of Achillea L. species native in Turkey against $\mathrm{H}_{2} \mathrm{O}_{2}$-induced oxidative damage in human erythrocytes and leucocytes. J Ethnopharmacol. 2005; 102: 221-227. [CrossRef]

[8] Benetis R, Radusiene J, Jakstas V, Janulis V, Poudziunuene G, Milasius A. Quantitative HPLC determination of phenolic compounds in yarrow. Pharm Chem J. 2008; 42: 51-54. [CrossRef]

[9] Shahidi F, Wanasundara P. Phenolic antioxidants. Crit Rev Food Sci Nutr. 1992; 32: 67-103. [CrossRef]

[10] de-Beer D, Joubert E, Gerlderblom WCA, Manley M. Phenolic compounds: A review of their possible role as in vivo antioxidants of wine. S Afr J Enol Vitic. 2002; 23: 48-61. [CrossRef]

[11] Bobis O, Dezmirean DS, Tomos L, Chirila F, Marghitas LA. Influence of phytochemical profile on antibacterial activity of different medicinal plants against gram-positive and gram-negative bacteria. Applied Biochem Micro. 2015; 51: 113-118. [CrossRef]

[12] Trumbeckaite S, Benetis R, Bumblauskiene L, Burdulis D, Janulis V, Toleikis A, Viskelis P, Jakstas V. Achillea millefolium L. s.l. herb extract: Antioxidant activity and effect on the rat heart mitochondrial functions. Food Chem. 2011; 127: 1540-1548. [CrossRef] 
[13] Raudonis R, Jakstas V, Burdulis D, Benetis R, Janulis V. Investigation of contribution of individual constituents to antioxidant activity in herbal drugs using post column HPLC method. Medicina (Kaunas). 2009; 45: 382-394. [CrossRef]

[14] Vitalini S, Beretta G, Iriti M, Orsenigo S, Basilico N, Dallacqua S, Lorizii M, Fico G. Phenolic compounds from Achillea millefolium L. and their bioactivity. Acta Biochim Pol. 2011; 58(2): 203-209.

[15] Bashi DS, Fazly BBS, Sahebkar A, Karimkhani MM, Ahmadi A. Investigation of optimal extraction, antioxidant, and antimicrobial activities of Achillea biebersteinii and A. wilhelmsii. Pharm Biol. 2012; 50: 1168-1176. [CrossRef]

[16] Baris D, Kizil M, Aytekin C, Kizil G, Yavuz M, Ceken B, Ertekin AS. In vitro antimicrobial and antioxidant activity of ethanol extract of three Hypericum and three Achillea species from Turkey. Int J Food Prop. 2011; 14: 339-355. [CrossRef]

[17] Ashgar M, Rasool N, Riaz M, Abass M, Mustafa AU, Adeel HM, Zubair M, Tareen RB, Rana UA, Ansari AR. Antioxidant and antimicrobial study of various parts of Achillea wilhelmsii (a medicinal plant). Oxid Commun. 2014; 37: 543-554.

[18] Gharibi S, Tabatabaei BES, Saeidi G, Goli SAH, Talebi M. Total phenolic content and antioxidant activity of three Iranian endemic Achillea species. Ind Crop Prod. 2013; 50: 154-158. [CrossRef]

[19] Benedec D, Vlase L, Oniga I, Mot AC, Damian G, Hanganu D, Duma M, Silaghi-Dumitrescu R. Polyphenolic composition, antioxidant and antibacterial activities for two Romanian subspecies of Achillea distans Waldst. et Kit. ex Willd. Molecules. 2013; 18: 8725-8739. [CrossRef]

[20] Marchart E, Kopp BC. Capillary electrophoretic separation and quantification of flavone-O and C-glycosides in Achillea setacea W. et K. J Chromatogr B. 2003; 792: 363-368. [CrossRef]

[21] Gökbulut A. Validated RP-HPLC method for quantification of phenolic compounds in methanol extracts of aerial parts and roots of Thymus sipyleus and evaluation of antioxidant potential. Trop J Pharm Res. 2015; 14: $1871-1877$. [CrossRef]

[22] Singleton VL, Orthofer R, Lamuela-Raventos RM. Analysis of total phenols and other oxidation substrates and antioxidants by means of Folin-Ciocalteu reagent. Method Enzymol. 1999; 299: 152-78. [CrossRef]

[23] Barros L, Baptista P, Ferreira ICFR. Effect of Lactarius piperatus fruiting body maturity stage on antioxidant activity measured by several biochemical assays. Food Chem Toxicol. 2007; 45: 1731-1737. [CrossRef]

[24] Re R, Pellegrin N, Proteggente A, Pannala A, Yang M, Rice-Evans C. Antioxidant activity applying an improved ABTS radical cation decolorization assay. Free Radical Bio Med. 1999; 26: 1231-1237. [CrossRef]

[25] IFPMA, "ICH validation of analytical procedures: text and methodology Q2 (R1)," Proceedings of the International Conference on Harmonization, IFPMA; 2005, Geneva, Switzerland. 